\title{
Service-Learning or Internship: A Mixed-Methods Evaluation of Experiential Learning Pedagogies
}

\author{
Miriam P. Leary (iD) and Lori A. Sherlock \\ Division of Exercise Physiology, Department of Human Performance and Applied Exercise Science, School of Medicine, \\ West Virginia University, PO Box 9225, Morgantown, WV 26506-9225, USA \\ Correspondence should be addressed to Miriam P. Leary; miriam.leary@hsc.wvu.edu
}

Received 6 August 2019; Revised 13 February 2020; Accepted 25 February 2020; Published 1 August 2020

Academic Editor: Christos Troussas

Copyright $\odot 2020$ Miriam P. Leary and Lori A. Sherlock. This is an open access article distributed under the Creative Commons Attribution License, which permits unrestricted use, distribution, and reproduction in any medium, provided the original work is properly cited.

\begin{abstract}
Experiential learning pedagogies, including internship and service-learning experiences, are becoming increasingly popular in higher education. An internship engages students with hands-on experiences that enhance their learning or skills within their fields of study. In contrast, service-learning is a type of experiential education in which students participate in service, typically within the community, and reflect on their involvement to gain further understanding of the discipline as well as its relationship to societal needs. To date, no study has directly compared these teaching modalities. Therefore, the present study systematically evaluated a service-learning experience against an internship experience using a mixed-methods model with the primary outcome being student self-efficacy. Sixteen exercise physiology students (13 females) completed a community-based wellness internship with a subgroup (nine students, 7 females) allocated to a service-learning component of internship designed to improve selfefficacy. At the end of the semester, students completed a 15-item online self-efficacy and satisfaction survey. Three focus groups were conducted in which 3-4 participants responded to a series of nine questions that explored their experience. Overall responses to the self-efficacy and satisfaction survey were favorable for both groups, but the internship group was more likely to agree or strongly agree with statements of self-efficacy. Focus groups found that the internship experience reinforced classroom learning, but the ability to work with different populations and ability levels was mentioned only by the service-learning group. Themes from reflective assignments, such as engaging with community members and professional exploration, were evident only in the service-learning group responses. Therefore, the findings indicate that service-learning reflection assignments successfully connect the service experience to relevant course outcomes promoting student development but may not improve self-reported self-efficacy beyond that of a typical internship experience.
\end{abstract}

\section{Introduction}

Experiential learning pedagogies shift learning from a teacher-centered, knowledge-transfer approach to the learner as an active participant in the learning process [1]. Experiential learning theory defines learning as "the process whereby knowledge is created through the transformation of experience" [2]. Experiential learning is correlated with an increased likelihood of attending graduate school, graduation rates, employment outcomes, and acquisition of skills that are relevant to career success, including communication skills, self-confidence, appreciation for community, and professional growth [3].
Experiential learning has been increasingly incorporated into higher education to advance curriculum goals (e.g., deepening understanding of academic content) [4]. Perhaps the most popular and familiar experiential learning experience is an internship. The goals of an internship are to engage students in learning activities for the purpose of providing them with hands-on experiences that enhance their understanding or skills within their fields of study and/ or vocational development [5]. However, in internship programs, students are the primary beneficiary, as opposed to the community. In contrast, service-learning is an alternative form of experiential learning in which students participate in service, typically within the community, with 
the potential for advancing their skills or knowledge base $[4,5]$.

Service-learning places equal focus on learning goals and service outcomes and places curricular concepts in the context of real-life situations [5]. It has been defined as a process of reflective education in which students learn civic or social responsibility through a scholarship of community engagement that embodies the principle of reciprocity, carefully balancing the service and learning goals so that both outcomes enhance one another [6]. By unifying what they are learning in the classroom with the service they are providing in the community, this method allows students to apply newly acquired skills and knowledge to address reallife needs in their own communities [5, 7].

A key component of service-learning is the role of reflection: students reflect on their involvement in such a way as to gain further understanding of course content and of the discipline as well as its relationship to societal needs $[4,5]$. Indeed, a hallmark pedagogical component of servicelearning is a structured reflection [4]. According to Kolb's Experiential Learning Theory, reflection is essential to the experiential learning process because it provides students a conceptual framework for learning from their service experience [2]. Qualitative and quantitative results emphasize the role of reflection as a means of connecting service experience to academic content [8]. Indeed, well-designed reflection promotes significant learning, including problem solving skills, higher order reason, integrative thinking, goal clarification, openness to new ideas, ability to adopt new perspectives, and systematic thinking $[9,10]$. Importantly, a meta-analysis found that the addition of a service-learning component translates into an improvement of $53 \%$ in learning outcomes [11].

Qualitative findings suggest service-learning is effective in part because it facilitates an increased sense of self-efficacy $[8,12]$. Self-efficacy refers to an individual's belief in their ability to successfully complete assigned tasks in specific situations. Increasing self-efficacy increases the probability that one's expected outcomes are the outcomes they can actually achieve [13]. Coined by social psychologist Bandura, self-efficacy has been the subject of research across disciplines. Generally, self-efficacy is an individual's perception of his/her ability to complete a particular endeavor and is strongly correlated to academic and work-related performance $[14,15]$. Self-efficacy in education focuses on students' self-beliefs as a principal component of academic motivation grounded on the assumption that the beliefs students create, develop, and hold to be true about themselves are vital determinants in their success or failure in school. For example, a self-efficacious student will recover quickly from setbacks to achieve his goals, whereas a student with low self-efficacy may be less likely to make a concerted effort if he believes he cannot be successful. People form selfefficacy perceptions by interpreting information from several sources, the most influential of which is the interpreted result of one's own performance [13]. A student that does poorly on a math test may believe he is "bad at math" and avoid the challenge of applying himself for future math exams. The reflective component of service-learning pedagogy offers students the opportunity to improve task and knowledge related self-efficacy by reinterpreting their experience and performance. For example, rather than merely receiving a low grade from an instructor, asking students to reflect and evaluate their own work can improve academic performance moving forward.

Courses that offer experiential learning and build student self-efficacy are critical to preparing students for professional endeavors and there is certainly justification for replacing traditional internships with service-learning programs to achieve these outcomes. However, a servicelearning course demands additional work for both the instructor (e.g., developing and reviewing reflective assignments) and students (e.g., completing the reflective assignments) beyond a typical internship course. Before implementing such curricular changes, evidence of improvements in students' self-efficacy and engagement is warranted. However, to our knowledge, no study has yet directly compared an internship experience with a matching service-learning experience.

Therefore, the present study sought to determine whether service-learning would improve students' self-efficacy and course-related outcomes beyond that of a standard internship. Two groups of students completed the same community-based wellness internship for a senior-level course, but one group received supplemental reflective assignments as part of the service-learning experience. The intention was to systematically evaluate the service-learning group (experimental) against the internship group (control) using a mixed-methods model with the primary outcome being student self-efficacy. Additionally, differences in course-related outcomes would be preliminarily explored by comparing responses between internships and servicelearning groups in focus group discussions.

\section{Methods}

This randomized, controlled education-based research study was approved by the Institutional Review Board (IRB 1809288247) of West Virginia University (WVU). Within the division of exercise physiology at WVU, most students aspire to become future healthcare practitioners (medicine, dental, physical therapy, occupational therapy, etc.). They are required to complete 180 hours of internship experience for their four credit (45 contact hours/1 credit hour) seniorlevel Professional Field Placement course.

Professional Field Placement is an internship course designed to provide students with hands-on learning experiences in Exercise Physiology specific settings. The purpose of this experiential learning is to enable students to gain valuable work experience while applying the knowledge gained throughout their coursework. It is intended to contribute meaningfully to their overall preparation by providing an opportunity for the practical application of skills and concepts learned in classes. Specific learning outcomes include the following:

(i) Take part in practical experiences within the Exercise Physiology environment 
(ii) Gain a more complete understanding of various roles of an Exercise Physiologist

(iii) Develop the ability to analyze and propose solutions to problems that may be encountered as an Exercise Physiologist

(iv) Develop a greater understanding of career options while more clearly defining personal career goals

(v) Improve responsibility and professionalism pertaining to both course work and industry

(vi) Develop and refine oral and written communication skills with potential employers, coworkers, and instructors

Previous recommendations for incorporating experiential learning opportunities sites the role of faculty in preparing students for internship, setting the expectations of internship with explicit contracts, and connecting classroom theory and internship practice [16]. Prior to starting the experiential learning opportunities, the codirectors of internship (coauthors on this work) prepared students by defining the purpose of the experience and highlighting the connection between classroom theory and internship practice in mandatory in-person meetings. Additionally, expectations were established with formal contracts signed between students and internship site supervisors. As part of the course, students were required to submit two self-reflections (at midterms and finals) that included a summary of activities, self-evaluation, areas of strength, and areas of weakness with steps outlined to correct weaknesses. Additionally, interns were evaluated by their internship site supervisor (at midterms and finals) in the areas of personal attributes, professionalism and work habits, professional ethics, initiative, learning capacity, internship knowledge, quality of work, team skills or group work, communication, and overall performance. This evaluation and feedback was given directly to the student and submitted to the course instructors.

During the spring 2019 semester, 16 students elected to participate in community-based wellness (CBW) internship experience which required interns to lead exercise classes for senior citizens, teach wellness classes for children and senior citizens, and/or deliver exercise programming to local firefighters. Of the $16 \mathrm{CBW}$ interns, nine (seven females) were allocated to a service-learning component of internship (CBW-SL group) which required 45 contact hours (or 1 credit hour) to be spent participating in learning modules and completing reflection assignments designed to improve self-efficacy and advance course-related outcomes. The remaining seven (six females) CBW interns served as "control" subjects who completed internship requirements but did not receive service-learning opportunities or complete reflection assignments outside of the midterm and final self-reflection. All students were informed that enrollment into the research project was voluntary and that refusal to participate would not affect class standing or grades and would involve no penalty. Written and verbal consent was obtained for all participants.
2.1. Service-Learning Intervention. Heffernan offered guidance on developing service-learning projects by implementing four basic principles: engagement (does the service meet public good?), reflection (is there a mechanism that encourages students to link their service experience to course content and reflect on why the service is important?), reciprocity (is there evidence that every individual functions as both teacher and learner?), and public dissemination (is the service work made public?) [7, 17]. These guidelines were incorporated into the service-learning project as described below. In line with additional recommendations, this service-learning experience was mandatory, initiated by a third party (university faculty), and had benefit to students (class credit) [18].

The purpose of the service-learning component was to enrich and contextualize the educational process that currently exists in the internship course through written reflections on the intentional consideration of an experience in the context of particular learning objectives. The servicelearning intervention incorporated four learning modules over the course of the semester (1/month, January 2019-April 2019). Learning modules were developed based on recommended guidelines for effective reflection activities [4]. The importance of the reflection activities cannot be overstated as reflection allows students to assess their achievements in the process of service-learning and determine their contributions to the community and beyond [19].

2.1.1. Exercise Programming for Older Adults. In the first module, CBW-SL interns participated in an "Exercise Prescription for Older Adults" workshop with an exercise physiology faculty member. This workshop emphasized incorporating the five components of physical fitness into exercise prescriptions and using unfamiliar movement patterns to incorporate cognitive training for seniors. Following the workshop, interns were assigned three research articles two of which were "Exercise, Cognition, and Aging" and "Effectiveness of a Timing and Coordination Group Exercise Program to Improve Mobility in CommunityDwelling Older Adults" as well as a third article of their choice from instructor-selected options [20-24]. Interns were to use what they learned in the workshop and readings to write a 2500 word essay as well as an exercise class plan that incorporated the 5 components of physical fitness with special emphasis on improving cognitive outcomes in seniors. Specific instructions to CBW-SL interns included: "the essay should include evidence supporting the relationship between exercise training and cognitive outcomes and argues for the justification of developing exercise programming for community-dwelling seniors ( 1000 words). Then, refer to your exercise class plan articulating the relevance of each exercise you've included, how it improves a component of physical fitness, and how it can improve cognitive outcomes ( 1000). Finish with a 500-word statement on how you will strive to incorporate this particular emphasis (exercise for cognition in aging) into your future professional career."

The purpose of this module was to have CBW-SL interns reflect on their role in promoting senior physical fitness and 
healthy cognition, both as current interns and future healthcare professionals. By arguing for the justification of community wellness programs for senior citizens, the students would understand the role of their internship in regard to civic engagement and social responsibility. This servicelearning assignment was implemented to increase professional development and citizenship, which has shown to be an outcome of service-learning programs [25].

2.1.2. Ripple Effect Mapping: Evaluating Program Impacts. In the second module, CBW-SL interns participated in a Ripple Effect Mapping (REM) session to capture programmatic impacts [26]. An exercise physiology faculty member trained in REM led the group through a hypothetical reflection on the wide-reaching effects of the interns' delivery of community-based exercise programming and education to local seniors. Following the session, the interns were to systematically evaluate their own impact by interviewing 3-4 community-dwelling individuals with whom they were regularly working as part of their internship. As a group, the interns developed a series of 10 questions to capture their impact. Interns conducted their interviews independently and captured their responses with REM. From the REM, interns wrote a 500-word abstract (purpose, methods, results, conclusion) summarizing their findings as well as a 500 -word statement on how they were impacted by these findings and how they would adjust their own practices and behaviors moving forward in the internship. Probing questions included: How will you change your programming? Will you incorporate more conversations like these throughout the semester? How has your understanding of and appreciation for what we're doing changed?

The purpose of this module was to encourage CBW-SL interns to understand and appreciate the larger impact of their internship experience. Reflecting on personal accounts from community-dwelling individuals would improve their experience and encourage interns to reevaluate their community role in their internship. This service-learning assignment was implemented to foster civic values and responsibility as well as to develop a greater understanding of their contribution to community welfare and social issues, which has shown to be an outcome of service-learning programs [27].

2.1.3. Client-Centered Self-Efficacy Case Study. In module 3, interns read "How to Enhance Self-efficacy and Resilience in Your Clients" published by the American Council on Exercise [28]. This article explained the concept of self-efficacy, presented a framework for enhancing self-efficacy and how to build self-efficacy in exercise training. Interns were instructed to apply some or all of the techniques presented in the article to training a single client with whom they regularly interact, document the effects over two weeks, and prepare a 6-minute case study "Ted Talk." Specific instructions to CBW-SL interns included: "In your presentation, make sure to give a brief background on the client, explain what techniques were used and how they were implemented, and share the documented findings regarding changes in self-efficacy. Highlight what you did or said that was specific to this client, whether it elicited the expected results, and, in your opinion, why or why not. State whether you will incorporate these methods as a practitioner moving forward in your career. As a 'Ted Talk' use storytelling to present your case study using innovative and engaging methods."

The purpose of this module was to introduce CBW-SL interns to the concept of self-efficacy and its role in community wellness programs. Applying these concepts and practices, and following with self-reflection, would encourage interns to appreciate the value of improved selfefficacy as individuals and as future healthcare practitioners. This service-learning assignment was implemented to develop leadership and oral communication skills as well as to develop skills related to the specific field of study by applying theory to practice, which has shown to be an outcome of service-learning programs [11].

2.1.4. Journaling/Free Response Reflection. In module 4, CBW-SL interns were given a series of open-ended questions to respond to regarding their experiences in the servicelearning component of the internship (e.g., How did this $C B W$ service-learning internship improve your knowledge and understanding of what you've learned in your required EXPH courses? How did this $C B W$ service-learning internship experience change your self-efficacy in terms of applying what you've learned in your required EXPH courses to "real-life" situations? How will you apply what you've learned from CBW service-learning internship moving forward?).

The purpose of this module was for CBW-SL interns to reflect on their internship experience, and drawing from previous modules, connect their experience with the overall purpose of the course, as described above. This servicelearning assignment was implemented to place their experience in the context of academic development and professional aspirations, which has shown to be an outcome of service-learning programs [29].

2.2. Evaluation. At the end of the semester, once internship requirements were completed and all interns had been formally evaluated for the course, all students completed postassessments including a self-efficacy and satisfaction survey and a focus group discussion. The self-efficacy and satisfaction survey was a 15-item online (Qualtrics, Inc., Provo, UT) survey with responses on a 7-point Likert scale from which students selected their level of agreement (strongly disagree-strongly agree). The survey incorporated questions from a validated Community Service Self-Efficacy Scale [30]. Three focus groups were conducted: the control group interns participated in a private focus group and CBW-SL interns were randomly divided into two private focus groups.

Qualitative research methods, including focus groups, can provide rich, descriptive data that can be missed when using quantitative methods. A semistructured protocol following standard focus group guidelines [31] was conducted by trained researchers $[31,32]$. Three private focus 
TABLE 1: Self-efficacy and satisfaction survey.

\begin{tabular}{|c|c|c|}
\hline Agree or strongly agree & $\begin{array}{l}\text { Control }(n=5) \\
\quad(\%)\end{array}$ & $\begin{array}{l}\text { CBW-SL }(n=8) \\
(\%)\end{array}$ \\
\hline $\begin{array}{l}\text { Because of this internship experience, if I choose to participate in experiential/service-learning in the } \\
\text { future, I will be able to make a meaningful contribution. }\end{array}$ & 80 & 63 \\
\hline $\begin{array}{l}\text { Because of this internship experience, in the future, I will be able to find experiential/service } \\
\text { opportunities which are relevant to my interests and abilities. }\end{array}$ & 100 & 63 \\
\hline $\begin{array}{l}\text { Because of this internship experience, I am confident that, through experiential/service-learning, I can } \\
\text { make a difference in my community. }\end{array}$ & 100 & 75 \\
\hline $\begin{array}{l}\text { Because of this internship experience, I am confident that I can help other individuals by participating } \\
\text { in experiential/service-learning activities. }\end{array}$ & 100 & 88 \\
\hline $\begin{array}{l}\text { Because of this internship experience, I am confident that in future experiential/service activities I will } \\
\text { be able to interact with relevant professionals in ways that are meaningful and effective. }\end{array}$ & 100 & 88 \\
\hline Through experiential/service-learning, I can apply my knowledge in ways that solve real-life problems. & 100 & 100 \\
\hline By participating in experiential/service-learning, I can help people help themselves. & 80 & 63 \\
\hline I am confident that I will participate in experiential/service-learning activities in the future. & 100 & 50 \\
\hline This internship opportunity increased my awareness of the larger EXPH community. & 80 & 63 \\
\hline $\begin{array}{l}\text { This internship opportunity helped me better understand how the community can benefit from EXPH } \\
\text { professionals. }\end{array}$ & 100 & 88 \\
\hline This internship helped me reflect on my life and goals. & 100 & 88 \\
\hline This internship has increased my interest in doing further service. & 100 & 88 \\
\hline I would recommend this internship experience to my friends. & 80 & 88 \\
\hline My experience with the community agency was positive. & 100 & 88 \\
\hline My experience with this internship experience has been positive. & 100 & 75 \\
\hline
\end{tabular}

groups of 3-4 participants responded to a series of nine questions, some with probing follow-ups, which explored their internship experience. A trained note taker took comprehensive notes on a laptop computer at each focus group, and proceedings were digitally audio recorded. These notes were reviewed by the focus group moderator for clarity, thoroughness, and accuracy. Only the CBW-SL interns were asked about the modules. Otherwise, all questions were the same between groups.

For qualitative data, Grounded Theory allows for an inductive theory-building approach which does not require a prior theory [33]. Using a heuristic or common-sense approach based in grounded theory, two independent researchers (with a tiebreaker when necessary) content analyzed to identify themes from the focus group data. The researchers discussed independent content analysis findings; however, due to the limited sample size saturation of repetitive concepts (i.e., point at which no new information, trends, or themes emerge from data) was not achieved [34]. The themes between groups (control and CBW-SL) were critically compared to determine differences between groups that were attributed to participation in the service-learning component.

\section{Results}

All participants remained in the research study throughout the entirety of the semester. However, only eight of the nine CBW-SL interns (89\%) and five of the seven Control interns (71\%) completed the postsemester self-efficacy survey. Overall responses to the self-efficacy and satisfaction survey were favorable for both groups, but the control group was more likely to agree or strongly agree with the survey questions (Table 1).

\subsection{Qualitative Responses}

3.1.1. Internship and Classroom Learning. Knowledge from specific classes (i.e., Exercise is Medicine and Strength and Conditioning) helped all participants in their internship, but both groups felt the internship required application of what they had learned in their exercise physiology courses and that this application increased their overall understanding of the curriculum, "Doing physical assessments really helped $m e$ " (CBW-SL participant). Implementing classroom learning into a professional setting meant adapting or individualizing to the patient/client which required all interns to have a thorough understanding of the material, "In real life I have to connect it and not just spit it out" (CBW-SL participant), as well as the ability to communicate with different populations, "You actually really have to know what you're talking about and explain it to people in way they can understand" (Control group participant).

When asked about the differences between classroom learning and internship experience, the control group seemed to put slightly more emphasis on the critical role of communication for internship, whereas the CBW-SL group emphasized the importance of application, "It makes way more sense now applying it to a real person" (CBW-SL participant). While both groups reported that combining classroom learning and internship application was helpful, the CBW-SL group specifically referred to the benefits of module 1, "When we go back to thinking about the research studies we read and use them in a setting. . we were able to apply that information immediately" (CBW-SL participant).

The internship experience increased both groups' selfefficacy in applying classroom learning to "real-life" situations, "No instructor to back me up really increased my selfefficacy" (Control participant) and "(I'm) not second guessing myself as much, I'm making decisions on my own" (CBW-SL 
participant). While the control group cited the role of communication, experimentation, and ownership, the CBW-SL mentioned greater independence and the resultant responsibility, "it forces you to go out on your own and figure it out" (CBW-SL participant) and "I could always ask for help, but it gave me more responsibility" (CBW-SL participant).

3.2. Internship Outcomes. In terms of developing new skills or abilities from the internship, the primary theme in both groups was that the internship experience reinforced classroom learning, “...internships helped reinforce” (Control participant). Both groups mentioned improved communication skills, but the control group referred to presentation skills, "I will use the skill moving into (graduate school), for presentation and educational tools" (Control participant), whereas the CBW-SL group cited professional communication, "seniors appreciate when you communicate properly" (CBW-SL participant). Indeed, the ability to work with different populations and ability levels was highlighted by the CBW-SL group, "I can now deal with lots of populations-I worked with seniors, kids, and have to tailor who you're working with" (CBW-SL participant) and "all (exercise class participants) were different levels and I had to program for an individual" (CBW-SL participant), but not mentioned by the control group. However, both groups reported the internship experience increased their independence, "Being on your own is unique to this internship and has helped, wish more people (could) experience it" (Control participant) and "The first time we had to do a GXT (graded exercise test) on someone not a student and without input" (Control participant), and confidence "I'm more mature" (Control participant), and "I'm more self-confident" (CBW-SL participant).

3.3. Moving Forward. All participants felt the internship helped to define their career interests, either reinforcing original interests or developing new ones, "More interest in personal training after working with firefighters" (Control participant), "Kind of led me towards a clinical setting where I can have an impact on people's lives" (CBW-SL participant), "This internship has made me think more broadly about what I want to do for the rest of my life." (CBW-SL participant), "Community experience has reinforced my interest in community nutrition." (CBW-SL participant). Some reflected on how it would influence their behavior as a professional, " $A$ class member was a veteran and kept talking about how he felt unheard by providers. So if he's feeling unheard, lots of people are-it changed my perspective." (Control participant) and participants in both groups felt it increased their professional confidence "Gave me more confidence to apply for a position at Healthworks (local fitness and rehabilitation center)" (Control participant) and "My confidence will allow me to easily interact with a variety of clients." (CBW-SL participant).

3.4. Feedback. The Control group reported the best part of the internship was the specific skills and abilities that they improved, "really enjoyed the lecturing aspect" (Control participant), "Favorite part was coaching" (Control participant), but the CBW-SL group felt the best part was the interaction with the patients/clients, "improvement in our clients, seeing their confidence grow" (CBW-SL participant), "relationships with the regulars, hearing their appreciation" (CBW-SL participant), and "getting to know the seniors better-they opened up and you develop a personal relationship with them" (CBW-SL participant). New professional interests were a favorite part of the program for the CBW-SL group as well, "gained a lot of perspective about what I want to do in the future" (CBW-SL participant). For both groups, the worst parts of the internship were site-specific including limited participation by patients/clients (e.g., having nothing to do, boredom).

Both groups would encourage the internship because it offered more independence and autonomy than other internship sites, citing "It's a unique experience being on your own" (Control participant) and "if you like doing your own thing than do this internship" (CBW-SL participant). However, both groups noted that it requires interns to be flexible and put in time outside of set hours, "if you're not willing to do the work on hours outside of set hours, do not do it"(Control participant) and "it was on me to prepare my lectures and workouts" (CBW-SL participant).

In reflecting on the modules, CBW-SL interns felt the assignments were time-consuming, but overall feedback was favorable. Module 1 was "really helpful to put everything together," module 2 "helped us to evaluate what this internship stands for-helps to see expectations and bigger picture," and module 3 was beneficial because it provided "hands on techniques."

\section{Discussion}

Experiential learning theory defines this type of learning as "the process whereby knowledge is created through the transformation of experience" [2]. This method of learning has been increasingly incorporated into higher education to deepen understanding of academic content. In the present study, both groups, an internship group and a servicelearning group, confirmed their experiential learning experience accomplished these hierarchical objectives. Their experiences required that they apply what they had learned in courses and that this application increased their overall understanding of the curriculum. One purpose of experiential learning is vocational development and in the present study, all participants felt the internship helped to define their career interests, either reinforcing original interests or developing new ones and felt it increased their professional confidence. Therefore, the primary purpose of this specific experiential learning course, to enable students to gain valuable work experience while applying the knowledge gained throughout their coursework, was achieved.

The objective of this study was to systematically evaluate the service-learning group (experimental) against the internship group (control) using a mixed-methods model with the primary outcome being student self-efficacy. Self-efficacy, an individual's perception of his/her ability to complete 
a particular endeavor, is strongly correlated to academic and work-related performance $[14,15]$. The reflective component of the service-learning experience was to allow students the opportunity to improve task and knowledge related selfefficacy by reinterpreting their mastery experience. In the present study, both groups reported increased self-efficacy in applying classroom learning to "real-life" situations, which is in agreement with previous findings [8]. However, contrary to expectations, the internship group was more likely than the service-learning group to agree with statements of selfefficacy in the survey. One possible explanation is the Dunning-Kruger effect which suggests those who are less competent have little insight into their own incompetence [35]. Perhaps, despite the two self-reflection assignments required by the course, the internship control group did not sufficiently reflect on their experience prior to completing the survey and rated themselves more highly than appropriate. Alternatively, it is possible that during the self-reflection assignments, the CBW-SL students were overly critical of themselves, focusing on their failures rather than the areas in which they were improving skills and knowledge, and were, therefore, less likely to highly agree with the self-efficacy statements. Despite this discrepancy, the focus group discussions confirmed both groups increased selfefficacy indicating the incorporation of service-learning reflection assignments is unnecessary for increasing selfefficacy in experiential learning. This finding could impact the ease of administering service-learning projects by reducing the time commitment of creating and assessing reflection activities. Additionally, it may promote participation in service-learning activities if time commitments outside of the actual service are condensed.

Overall, both experiential learning methods were reported by participants to increase overall understanding and application of classroom knowledge to "real-life" situation. They also reported communication skills, specifically the ability to communicate with different populations, as well as independence and confidence. In agreement with the present study, a mixed-methods study found students expect to develop a skills set through service-learning, including work place skills, interpersonal skills, written and oral communication skills, and leadership skills [36]. Other studies have found similar results for service-learning outcomes including public speaking, time management, and presentation skills [19].

In focus group discussions, responses from the CBW-SL group incorporated themes from the reflective assignments that were not evident in the control group discussion. First, the CBW-SL group referred to the ability to work with different populations and ability levels (incorporated into in module 1 and 3 ). These results are supported by a recent review of medical educational experiential learning which found favorable self-reported outcomes in intra- and interpersonal skills as well as civic engagement and social responsibility [37]. Previous research which has emphasized the role of reflection as a means of connecting service experience to academic content [8] and shown well-designed reflection promotes significant learning, including integrative thinking and ability to adopt new perspectives and higher order thinking skills (e.g., analysis, synthesis, and evaluation) $[9,10]$.

Additionally, the CBW-SL group was more likely to reflect on developments to professional interests and goals (incorporated into modules 1 and 3) which agrees with previous findings that reflection can lead to goal clarification, especially career goals and new perspectives $[9,10,38]$. These findings have been confirmed by previous work that found improvements in academic knowledge and professional skills [37].

Finally, the CBW-SL group felt the best part of their experience was the interaction with patients/clients (incorporated into modules 2 and 3 ) which is supported by previous service-learning research findings including the development of new friendships and caring for others $[19,39]$. Indeed, in service-learning programs, those being served in the community teach lessons to those serving them and through this reciprocity, students gain a greater sense of belonging and responsibility as members of a larger community $[38,40]$. While not investigated in the current study, this could translate to long-lasting impacts as previous work has shown service-learning leads to higher participation in general volunteering [18] and fosters capability and commitment in students to act as agents of social change in the long term [36]. These CBW-SL specific results (i.e., working work with different populations and ability levels, developing professional interests and goals, and valuing patients/ clients interactions) are key outcomes to the course and overall student development that should be prioritized. Therefore, the incorporation of reflection assignments as modules proved beneficial.

As described, this mixed-methods research study was implemented to determine whether the course curriculum should be amended to include a service-learning component. Courses that offer experiential learning and build student self-efficacy are critical to preparing students for professional endeavors. In the present service-learning model, while there were criticisms to the time spent on reflective assignments, the general feedback was favorable. Module 1 was "really helpful to put everything together," module 2 "helped us to evaluate what this internship stands for-helps to see expectations and bigger picture," and module 3 was beneficial because it provided "hands on techniques." The incorporation of service-learning assignments demands additional work for both the instructor (e.g., developing and reviewing reflective assignments) and students (e.g., completing the reflective assignments) beyond a typical internship course. These findings suggest that incorporating less time-consuming reflective assignments that still connect to field work might achieve similar results without burdening the students. One method for accomplishing this could be working in an e-learning platform, especially one that leads to higher order cognition and enhanced learning. Developing integrated educational environments using e-learning platforms that incorporate valuable features of intelligent adaptive and collaborative learning can support the learning process and assist students in their efforts while reducing the overall time commitment of instructors as well [41-45]. 
To our knowledge, this is the first study to directly compare an internship experience with a matching servicelearning experience. However, this study presented its own limitations. First, the sample size between groups was small and limited to a narrow field of students in communitybased wellness. Therefore, the wide application of findings to other disciplines should be cautioned. Additionally, while there was a mix of genders within each group, there were fewer male students overall which limits the generalizability of these findings. Further, the present study used surveys and focus group data to evaluate self-efficacy, but additional and perhaps more direct measures could be considered in future research.

\section{Conclusion}

The present study sought to determine whether servicelearning would improve students' self-efficacy beyond that of a standard internship. In systematically evaluating the service-learning group (experimental) against the internship group (control), both groups increased self-efficacy, but there was no difference between groups, indicating the incorporation of service-learning reflection assignments is unnecessary for increasing self-efficacy in experiential learning. However, themes from reflective assignments were evident in the service-learning group responses that were not evident in the control group discussion, confirming the role of reflection as a means of connecting service experience to relevant course outcomes. Overall, findings suggest that incorporating small reflective assignments to experiential learning courses would improve key outcomes related to the course and student development.

\section{Data Availability}

The data used to support the findings of this study are available from the corresponding author upon request.

\section{Conflicts of Interest}

The authors declare that they have no conflicts of interest.

\section{References}

[1] A. Y. Kolb and D. A. Kolb, Learning Styles and Learning Spaces: A Review of the Multidisciplinary Application of Experiential Learning Theory in Higher Education, Nova Science Publishers, Inc., Hauppauge, NY, USA, 2006.

[2] D. A. Kolb, Experiential Learning: Experience as the Source of Learning and Development, 256 pages, Prentice-Hall, Englewood Cliffs, NJ, USA, 1984.

[3] L. A. Bradberry and J. De Maio, "Learning by doing: the longterm impact of experiential learning programs on student success," Journal of Political Science Education, vol. 15, no. 1, pp. 94-111, 2019.

[4] J. A. Hatcher and R. G. Bringle, "Reflection: bridging the gap between service and learning," College Teaching, vol. 45, no. 4, pp. 153-158, 1997.

[5] A. Furco, "Service learning: a balanced approach to experiential education," Learn and Serve America: Higher Eduation, pp. 2-6, The Corporation For National Service, Seattle, WA, USA, 1996.

[6] D. Caspersz, D. Olaru, and L. Smith, "Striving for definitional clarity: what is service learning?" The Australasian Journal of University-Community Engagement, vol. 7, no. 1, 2012.

[7] A. L. Phelps, "Stepping from service-learning to servicelearning pedagogy," Journal of Statistics Education, vol. 20, no. 3, 2012.

[8] A. W. Astin, L. J. Vogelgesang, E. K. Ikeda, and J. A. Yee, How Service Learning Affects Students, p. 144, Higher Education Research Institute, University of California, Oakland, CA, USA, 2000.

[9] J. Eyler and D. Giles, "Where's the learning in servicelearning?" The Jossey-Bass Higher and Adult Education Seriesp. 315, 1st edition, Jossey-Bass, San Francisco, CA, USA, 1999.

[10] D. Conrad and D. Hedin, "Learning from service: experience is the best teacher-or is it," Combining service and learning, pp. 87-98, National Society for Internships and Experiential Education, Raleigh, NC, USA, 1990.

[11] J. M. Novak, V. Markey, and M. Allen, "Evaluating cognitive outcomes of service learning in higher education: a metaanalysis," Communication Research Reports, vol. 24, no. 2, pp. 149-157, 2007.

[12] C. Hilarski, "Building student self-efficacy and mastery of skills through service learning partnership," in Proceedings of the Coalition of Urban and Metropolitan Universities National Conference, pp. 25-34, Chattanooga, TN, USA, October 2013.

[13] A. Bandura, "Self-efficacy: toward a unifying theory of behavioral change," Psychological Review, vol. 84, no. 2, pp. 191-215, 1977.

[14] A. D. Stajkovic and F. Luthans, "Self-efficacy and work-related performance: a meta-analysis," Psychological Bulletin, vol. 124, no. 2, pp. 240-261, 1998.

[15] K. D. Multon, S. D. Brown, and R. W. Lent, "Relation of selfefficacy beliefs to academic outcomes: a meta-analytic investigation," Journal of Counseling Psychology, vol. 38, no. 1, pp. 30-38, 1991.

[16] J. K. Sosland and D. J. Lowenthal, "The forgotten educator: experiential learning's internship supervisor," Journal of Political Science Education, vol. 13, no. 1, pp. 1-14, 2017.

[17] K. Heffernan, Fundamentals of Service-Learning Course Construction, Campus Compact, Brown University, Providence, RI, USA, 2001.

[18] D. Haski-Leventhal, H. GrÖNlund, K. Holmes et al., "Servicelearning: findings from a 14-nation study," Journal of Nonprofit \& Public Sector Marketing, vol. 22, no. 3, pp. 161-179, 2010.

[19] M. M. Helms, R. M. Rutti, A. A. Hervani, J. LaBonte, and S. Sarkarat, "Implementing and evaluating online service learning projects," Journal of Education for Business, vol. 90, no. 7, pp. 369-378, 2015.

[20] J. N. Barnes, "Exercise, cognitive function, and aging," Advances in Physiology Education, vol. 39, no. 2, pp. 55-62, 2015.

[21] R. L. Johnson, A. T. Sadosty, A. L. Weaver, and D. G. Goyal, "To sit or not to sit?" Annals of Emergency Medicine, vol. 51, no. 2, pp. 188-193, 2008.

[22] H. Arrieta, C. Rezola-Pardo, S. M. Gil, J. Irazusta, and A. Rodriguez-Larrad, "Physical training maintains or improves gait ability in long-term nursing home residents: a systematic review of randomized controlled trials," Maturitas, vol. 109, pp. 45-52, 2018.

[23] S. M. Yates and T. A. Dunnagan, "Evaluating the effectiveness of a home-based fall risk reduction program for rural 
community-dwelling older adults," The Journals of Gerontology Series A: Biological Sciences and Medical Sciences, vol. 56, no. 4, pp. M226-M230, 2001.

[24] J. S. Brach, S. Perera, S. Gilmore et al., "Effectiveness of a timing and coordination group exercise program to improve mobility in community-dwelling older adults," JAMA Internal Medicine, vol. 177, no. 10, pp. 1437-1444, 2017.

[25] R. Parker-Gwin, "Connecting service to learning: how students and communities matter," Teaching Sociology, vol. 24, no. 1, pp. 97-101, 1996.

[26] M. Emery, L. Higgins, S. Chazdon, and D. Hansen, "Using Ripple effect mapping to evaluate program impact: choosing or combining the methods that work best for you," Journal of Extension, vol. 53, no. 2, 2015.

[27] B. M. Harward and L. S. Albert, "Service and service-learning," American Association for Higher Education Bulleting, vol. 46, pp. 9-11, 1994.

[28] C. Padgett, "How to enhance self-efficacy and resilience in your clients," American Council on Exercise, San Diego, CA, USA, 2019.

[29] A. W. Astin and L. J. Sax, "How undergraduates are affected by service participation," Journal of College Student Development, vol. 39, no. 3, p. 251, 1998.

[30] R. N. Reeb, R. M. Katsuyama, J. A. Sammon, and D. S. Yoder, "The community service self-efficacy scale: evidence of reliability, construct validity, and pragmatic utility," Michigan Journal of Community Service Learning, vol. 5, no. 1, pp. $48-57,1998$.

[31] I. McLafferty, "Focus group interviews as a data collecting strategy," Journal of Advanced Nursing, vol. 48, no. 2, pp. 187-194, 2004.

[32] P. Mason, C. Butler, and S. Rollnick, Health Behavior Change: A Guide for Practitionersp. 221, 2nd edition, Churchill Livingstone/Elsevier, London, UK, 2010.

[33] J. Corbin and A. Strauss, "Grounded theory research-procedures, canons and evaluative criteria," Zeitschrift Fur Soziologie, vol. 19, no. 6, pp. 418-427, 1990.

[34] M. B. Miles and A. M. Huberman, Qualitative Data Analysis: An Expanded Sourcebookp. 338, 2nd edition, Sage Publications, Thousand Oaks, CA, USA, 1994.

[35] J. Kruger and D. Dunning, "Unskilled and unaware of it: how difficulties in recognizing one's own incompetence lead to inflated self-assessments," Journal of Personality and Social Psychology, vol. 77, no. 6, pp. 1121-1134, 1999.

[36] D. Caspersz and D. Olaru, "The value of service-learning: the student perspective," Studies in Higher Education, vol. 42, no. 4, pp. 685-700, 2017.

[37] T. Stewart and Z. C. Wubbena, "A systematic review of service-learning in medical education: 1998-2012," Teaching and Learning in Medicine, vol. 27, no. 2, pp. 115-122, 2015.

[38] B. Jacoby, "Service-learning in higher education: concepts and practices," The Jossey-Bass Higher and Adult Education Series, Wiley, Hoboken, NJ, USA, 1996.

[39] M. D. McCarthy, "One-time and short-term service-learning experiences," Service-Learning in Higher Education: Concepts and Practices, pp. 113-134, Jossey-Bass, San Francisco, CA, USA, 1996.

[40] T. K. Stanton, D. E. Giles Jr., and N. I. Cruz, "Service-learning: a movement's pioneers reflect on its origins, practice, and future," Jossey-Bass Higher and Adult Education Series, Wiley, Hoboken, NJ, USA, 1999.

[41] A. Krouska, C. Troussas, M. Virvou, and C. K. Fragkakis, "Applying skinnerian conditioning for shaping skill performance in online tutoring of programming languages," in
Proceedings of the 2018 9th International Conference on Information, Intelligence, Systems and Applications (IISA), July 2018.

[42] A. Krouska, C. Troussas, and M. Virvou, "A literature review of social networking-based learning systems using a novel ISO-based framework," Intelligent Decision Technologies, vol. 13, no. 1, pp. 23-39, 2019.

[43] A. Krouska, C. Troussas, and M. Virvou, "SN-Learning: an exploratory study beyond e-learning and evaluation of its applications using EV-SNL framework," Journal of Computer Assisted Learning, vol. 35, no. 2, pp. 168-177, 2019.

[44] C. Troussas, A. Krouska, M. Virvou, and E. Sougela, "Using hierarchical modeling of thinking skills to lead students to higher order cognition and enhance social e-learning," in Proceedings of the 2018 9th International Conference on Information, Intelligence, Systems and Applications (IISA), July 2018.

[45] C. Troussas, A. Krouska, and C. Sgouropoulou, "Collaboration and fuzzy-modeled personalization for mobile gamebased learning in higher education," Computers \& Education, vol. 144, Article ID 103698, 2020. 